Terakreditasi

Ditjen Penguatan Riset dan Pengembangan, Kemenristekdikti Keputusan No: 21/E/KPT/2018, Tanggal 9 Juli 2018
September 2020, 7(3):238-346

DOI: http://dx.doi.org/10.33772/jitro.v7i3.12203

http://ojs.uho.ac.id/index.php/peternakan-tropis

\title{
Kualitas Semen Beku Sexing Sapi Peranakan Ongole Menggunakan Volume Semen A wal Yang Berbeda
}

\author{
Irvan Mardi ${ }^{1)}$. Aulia Puspita Anugra Yekti' ${ }^{2}$, Kuswati' ${ }^{2}$, Muchamad Luthfi' ${ }^{3)}$, \\ Trinil Susilawati ${ }^{2 *}$ \\ 1) Mahasiswa Fakultas Peternakan, Universitas Brawijaya \\ Jl. Veteran, Kec. Lowokwaru, Kota Malang, Jawa Timur 65145 \\ ${ }^{2)}$ Dosen Fakultas Peternakan, Universitas Brawijaya \\ Jl. Veteran, Kec. Lowokwaru, Kota Malang, Jawa Timur 65145 \\ ${ }^{3)}$ Loka Penelitian Sapi Potong Grati, Pasuruan \\ Jl. Pahlawan Grati, Bebekan Lor, Kec. Grati, Pasuruan, Jawa Timur 67184 \\ *Email Korespondensi: irvanmardi06@gmail.com \& tsusilawati@ub.ac.id
}

(Diterima 22-05-2020; disetujui 25-09-2020)

\begin{abstract}
ABSTRAK
Inseminasi buatan dengan menggunakan semen sexing diharapkan menghasilkan pedet dengan jenis kelamin sesuai harapan. Tujuan dari penelitian ini adalah untuk mengetahui kualitas, proporsi, dan jumlah produksi straw sexing menggunakan metode sentrifugasi gradien densitas percoll dengan volume awal semen yang berbeda. Penelitian dilakukan di Loka Penelitian Sapi Potong, Kecamatan Grati, Kabupaten Pasuruan dan Laboratorium Reproduksi Ternak, Fakultas Peternakan Universitas Brawijaya, Malang. Materi yang digunakan adalah semen sapi peranakan ongole berumur berkisar lima tahun dan bobot badan berkisar $700 \mathrm{~kg}$ sebanyak tiga ekor, motilitas massa $\geq 2+$ dan motilitas individu $\geq 70 \%$. Metode yang digunakan adalah eksperimental dengan tiga perlakuan volume awal saat sexing, yaitu 1 (P1); 1,5 (P2); dan 2 (P3) ml dengan ulangan 11 kali (ulangan berfungsi sebagai kelompok). Data dianalisa menggunakan Rancangan Acak Kelompok (RAK). Hasil penelitian menunjukkan bahwa perbedaan volume awal semen tidak berpengaruh (menurun) terhadap motilitas, viabilitas, abnormalitas, konsentrasi, total spermatozoa motil, recovery rate dan proporsi spermatozoa $(\mathrm{P}>0,05)$. Pengaruh yang sangat nyata (meningkat) terhadap jumlah produksi straw $(\mathrm{P}<0,01)$. Ulangan penelitian ini memberikan pengaruh yang sangat nyata (meningkat) terhadap kualitas (motilitas, konsentrasi, viabilitas, abnormalitas, total spermatozoa motil, RR, proporsi dan jumlah straw) dan proporsi spermatozoa X dan Y $(\mathrm{P}<0,01)$. Total spermatozoa motil setiap perlakuan telah memenuhi nilai harapan (10 juta/straw). Proporsi spermatozoa X dan Y telah memenuhi nilai harapan (80\%:20\%).
\end{abstract}

Kata Kunci: kualitas, proporsi, semen beku sexing, straw

\begin{abstract}
Artificial insemination using sexing semen is expected to produce calves with the expected sex. The aim of this study was to determine the quality, proportion, and quantity of sexing semen production using the percoll density gradient centrifugation method with different initial semen volumes. The research was conducted at the Beef Cattle Research, Grati District, Pasuruan Regency, East Java Province, Indonesia, and the Animal Reproduction Laboratory, Faculty of Animal Science, University of Brawijaya, Malang, East Java Province, Indonesia. The material used was semen from three Ongole crossbred bull aged around five years and the bodyweight of around $700 \mathrm{~kg}$, mass motility of $\geq 2+$, and individual motility $\geq 70 \%$. The method used was experimental with three initial volume treatments during sexing, namely 1 (P1); 1.5 (P2), and 2 (P3) ml with 11 replications (replications function as groups). The data were analyzed using a randomized block design (RBD). The results showed that the treatment of differences in initial semen volume did not affect motility, viability, abnormalities, concentration, total motile sperm, recovery rate, and proportion of sperm $(\mathrm{P}>0.05)$. On the other hand, the difference in the initial volume of semen had a very significant effect (increased) on the amount of frozen semen production $(\mathrm{P}<0.01)$. Repeated research also had a very significant effect (increased) on the semen quality (motility, concentration, viability, abnormality, total sperm motility, recovery rate proportion, and straw production) and the proportion of spermatozoa $X$ and $Y(P<0.01)$. The total motile sperm for each treatment had met the expected value $(10$ million/straw). Proportions of spermatozoa $\mathrm{X}$ and $\mathrm{Y}$ have met the expected value (80\%: 20\%).
\end{abstract}

Keywords: proportion, quality, sexing frozen semen, straw 


\section{PENDAHULUAN}

Inseminasi buatan menggunakan semen sexing telah terbukti dapat meningkatkan efisiensi pada usaha peternakan sapi. IB dapat ditingkatkan nilainya dengan menghasilkan bibit unggul dengan jenis kelamin yang sesuai dengan tujuan pemeliharaan, misalnya untuk potong dibutuhkan sapi pejantan dan untuk perah dibutuhkan sapi betina. Sexing dapat dilakukan dengan berbagai metode, diantaranya sentrifugasi gradien densitas percoll (SGDP) yang hasilnya lebih baik, dapat dibuat lebih mudah dan dapat memisahkan spermatozoa $X$ dan Y sebesar 80\% (Susilawati, 2014). Hasil penelitian Fernanda et al. (2014) menunjukkan bahwa setelah thawing semen sexing, persentase motilitas spermatozoa $\mathrm{X}$ sebesar $35 \%$ dan spermatozoa Y sebesar $40 \%$. Hasil penelitian Susilawati et al. (2017) menyatakan bahwa motilitas spermatozoa X dan Y semen sexing SGDP post thawing masing-masing adalah $31,45 \pm 7,20 \%$ dan $27,45 \pm 8,69 \%$. Hasil penelitian Mahfud et al. (2019) menyatakan bahwa konsentrasi spermatozoa sexing beku sebanyak 12,125 juta/straw.

Standar kosentransi spermatozoa hasil sexing sesuai Standar Nasional Indonesia (SNI) belum ada sampai saat ini dan konsentrasi spermatozoa untuk semen beku sapi sesuai Standar Nasional Indonesia (SNI 01-4869.12017). Semen beku yang dapat didistribusikan dan diinseminasikan harus memiliki post thawing motility minimal sebesar $40 \%$ dan konsentrasi spermatozoa sebesar $25 \mathrm{juta} /$ straw atau 25 juta/0,25 ml. Upaya memenuhi persyaratan mutu (konsentrasi spermatozoa) semen beku yang telah ditetapkan sesuai SNI dan kerena belum adanya konsentrasi spermatozoa hasil sexing SGDP sesuai SNI, maka penelitian ini perlu dilakukan.

\section{MATERI DAN METODE}

\section{Lokasi dan Waktu}

Penelitian ini dilaksanakan di Loka Penelitian Sapi Potong, Jalan Pahlawan No. 2, Desa Klindungan, Kecamatan Grati, Kabupaten Pasuruan pada bulan Januari sampai Maret 2020, sedangkan penelitian mengenai uji proporsi spermatozoa $\mathrm{X}$ dan $\mathrm{Y}$ dilaksanakan di Laboratorium Reproduksi Ternak, Fakultas Peternakan, Universitas Brawijaya, Malang.

\section{Materi}

Sampel semen yang digunakan pada penelitian ini adalah semen yang berasal dari tiga ekor pejantan sapi peranakan ongole (PO) berumur berkisar lima tahun dengan bobot badan berkisar $700 \mathrm{~kg}$. Semen yang digunakan memiliki kriteria motilitas massa $\geq+2$, motilitas individu $\geq 70 \%$, viabilitas $\geq 80 \%$, dan abnormalitas <20\% Percoll (Sigma-Adrich, Germany), dan pengencer Andromed $^{\circledR}$ (Minitube, USA).

\section{Metode}

Metode penelitian yang digunakan adalah metode eksperimental dengan tiga perlakuan volume semen awal saat sexing, yaitu 1 (P0); 1,5 (P1); dan $2 \mathrm{ml}$ (P2). Setiap perlakuan dilakukan pengulangan sebanyak 11 kali (ulangan sebagai kelompok). Data dianalisa menggunakan Rancangan Acak Kelompok (RAK). Parameter yang diukur adalah persentase motilitas individu, viabilitas, abnormalitas, konsentrasi, total spermatozoa motil, recovery rate, proporsi spermatozoa $\mathrm{X}$ dan Y dan produksi semen beku.

\section{Prosedur Penelitian}

Penelitian ini menggunakan 10 densitas gradien dengan konsentrasi 20; 25; 30; 35; 40; $45 ; 50 ; 55 ; 60$; dan $65 \%$. Masing-masing densitas Percoll ditambahkan pengencer Andromed $^{\circledR}$ dengan volume $0,5 \mathrm{ml}$ dibuat $10 \mathrm{n}$ gradien dari $65 \%$ sampai dengan $20 \%$. Semen dengan volume yang berbeda dimasukkan ke dalam tabung reaksi yang telah berisi larutan percoll+pengencer dan dilakukan sentrifugasi dengan kecepatan $2250 \mathrm{rpm}$ selama lima menit. Larutan di lapisan atas diambil sebanyak $2 \mathrm{ml}$ (spermatozoa Y) dan $2 \mathrm{ml}$ bagian bawah (spermatozoa $\mathrm{X}$ ) ditempatkan dalam tabung reaksi yang berbeda yang berisi $3 \mathrm{ml}$ pengencer setelah sentrifugasi. Pencucian dengan sentrifugasi kecepatan $1500 \mathrm{rpm}$ selama tiga menit. Bagian atas (supernatant) dibuang dan disisakan endapan (precipitate) sebanyak $1 \mathrm{ml}$ di dasar tabung. Supernatan ditambahkan pengencer dengan prediksi konsentrasi 25 juta/ml dan dilanjutkan pada tahap pembekuan.

Tahap pembekuan diawali dengan memasukkan semen sexing ke dalam tabung reaksi yang direndam dalam waterbath suhu $30^{\circ} \mathrm{C}$ dan suhu diturunkan sampai suhu $4^{\circ} \mathrm{C}$ (refrigerator atau cool tub). Uji motilitas 
individu dilakukan sebelum proses pembekuan untuk memastikan kualitas semen sexing. Proses filling and sealing dilakukan pada suhu mendekati suhu refrigerator. Straw yang telah berisi semen dilakukan pre freezing (penguapan diatas nitrogen cair) pada suhu $-140^{\circ}$ selama sembilan menit untuk penyesuaian suhu semen sebelum direndam dalam nitrogen cair. Proses freezing dengan merendam straw berisi semen hasil sexing dalam container yang berisi nitrogen cair dengan suhu $-19^{\circ} \mathrm{C}$ selama minimal 24 jam dan selanjutnya, dilakukan pengamatan uji kualitas dan proporsi spermatozoa X dan Y.

\section{Variabel Penelitian}

Variabel yang diamati dalam penelitian ini, meliputi:

\section{Motilitas Individu (\%)}

Motilitas individu spermatozoa diamati menggunakan mikroskop cahaya (CX-23, Olympus, Jepang) dengan perbesaran 400X. Penentuan persentase motilitas dilakukan dengan pengamatan lima lapang pandang dan rata-rata diambil dari lima lapang pandang tersebut (SNI 01-4869.1-2017).

\section{Konsentrasi Spermatozoa}

Proses perhitungan konsentrasi menggunakan haemocytometer (Marienfield, Germany). Semen diencerkan 200 kali dengan larutan fisiologis $\mathrm{NaCl}$ 0,9\% dan dikocok membentuk angka delapan selama dua menit. Semen dibuang 1-2 tetes dan semen diteteskan diatas kamar hitung haemocytometer yang ditutupi cover glass. Spermatozoa diamati pada lima kotak dengan arah diagonal menggunakan mikroskop dengan perbesaran 400x. Perhitungan konsentrasi spermatozoa menurut Susilawati (2011).

Konsentrasi $=$ Total spermatozoa $\times 10^{6}$

\section{Viabilitas spermatozoa (\%)}

Pengamatan viabilitas spermatozoa dilakukan untuk mengetahui persentase spermatozoa yang hidup dengan preparat ulas atau smear. Preparat ulas dibuat dengan mencampur satu tetes semen dan satu tetes eosin-negrosin dengan ose, kemudian dibuat smear dengan object glass dengan kemiringan $45^{\circ} \mathrm{C}$. Jumlah spermatozoa yang diamati minimal sebanyak 200 spermatozoa menggunakan mikroskop cahaya dengan pembesaran 400x (Susilawati, 2011).
$\%$ Viabilitas $=\frac{\text { spermatozoa hidup }}{\text { jumlah total spermatozoa }} \times 100 \%$

\section{Abnormalitas spermatozoa (\%)}

Abnormalitas spermatozoa dievaluasi menggunakan preparat ulas untuk pengamatan viabilitas. Morfologi spermatoza abnormal (tidak ada ekor, abnormal kepala, bentuk ekor abnormal, bentuk ekor abnormal dengan adanya sitoplasmic droplet pada bagian proximal dan bentuk abnormal ekor dengan distal droplet) diamati dengan mikroskop cahaya dengan perbesaran 400x. Jumlah spermatozoa yang diamati minimal sebanyak 200 spermatozoa dan dinyatakan dalam persen (\%) (Noakes et al., 2009; Susilawati \& Yekti, 2018).

$\%$ Abnormalitas $=\frac{\text { spermatozoa abnormal }}{\text { jumlah total spermatozoa }} \times 100 \%$

\section{Total Spermatozoa Motil (TSM)}

Total spermatozoa motil adalah perhitungan total spermatozoa motil yang diperoleh dari perkalian antara persentase motilitas individu spermatozoa dengan konsentrasi spermatozoa dalam juta/straw. Perhitungan total spermatozoa yang motil menurut Susilawati (2011), sebagai berikut:

$$
\mathrm{TSM}(\mathrm{juta} / \text { staw })=\mathrm{KS} \times \mathrm{MS}
$$

Keterangan:

KS : konsentrasi spermatozoa (juta)

MS : motilitas spermatozoa (\%)

\section{Recovery Rate (RR)}

Recovery Rate merupakan pemulihan spermatozoa setelah pembekuan dengan pembagian antara motilitas spermatozoa setelah thawing dengan motilitas spermatozoa segar (Garner \& Hafez, 2000). Persentase RR dapat dihitung dengan rumus, sebagai berikut:

$$
\text { Recovery Rate }=\frac{\text { Motilitas Semen Beku }}{\text { Motilitas Semen }} \times 100 \%
$$

\section{Proporsi spermatozoa}

Solihati et al. (2017) menyatakan bahwa metode morfometrik sebagai dasar untuk aplikasi sexing melalui identifikasi ukuranukuran kepala spermatozoa. Identifikasi morfometri spermatozoa menggunakan mikroskop cahaya (235, Olympus, Jepang) dengan perbesaran 400x yang dilengkapi micrometer okuler. Pengukuran morfometri, meliputi panjang dan lebar kepala spermatozoa. Penetapan spermatozoa $X$ adalah jika panjang kepala lebih besar dari rata-rata dan spermatozoa 
Y adalah jika panjang kepala lebih kecil dari rata-rata. Data yang diperoleh dilakukan perhitungan persentase spermatozoa X dan $\mathrm{Y}$.

\section{Produksi straw semen sexing.}

Jumlah straw yang dihasilkan setelah proses pembekuan dapat diketahui dengan perhitungan konsentrasi semen cair yang dibagi dengan konsentrasi spermatozoa didalam straw sesuai dengan SNI 01-4869.1-2017, yaitu 25 juta/straw.

$$
\text { Produksi Straw }=\frac{\text { volume total }}{\text { volume } \text { straw }}
$$

\section{Analisis Data}

Data penelitian dianalisis menggunakan RAK dan 11 ulangan sebagai blok pada setiap perlakuannya untuk mengetahui pengaruh perbedaan setiap perlakuan. Uji Chi-square untuk menguji kesesuaian dengan SNI.

\section{HASIL DAN PEMBAHASAN}

\section{Kualitas Semen}

Kualitas semen merupakan salah satu faktor yang menjadi pertimbangan untuk melakukan teknologi IB. Proses pembekuan semen dilakukan dengan metode konvensional menggunakan proses pembekuan bertingkat (slow freezing). Parameter pengamatan yang dilakukan terhadap semen sexing beku, diantaranya motilitas individu (\%), konsentrasi, viabilitas (\%), abnormalitas (\%), total spermatozoa motil, recovery rate, dan proporsi spermatozoa semen sexing beku.

Tabel 1. Kualitas semen perlakuan

\begin{tabular}{cccc}
\hline Ulangan & $\begin{array}{c}\text { Kode } \\
\text { Pejantan }\end{array}$ & $\begin{array}{c}\text { Motilitas } \\
\text { Massa }\end{array}$ & $\begin{array}{c}\text { Motilitas } \\
\text { Individu } \\
(\%)\end{array}$ \\
\hline 1 & 15.7 .9 & $2+$ & 78 \\
2 & 15.7 .9 & $2+$ & 78 \\
3 & 15.7 .9 & $2+$ & 72 \\
4 & 15.7 .9 & $2+$ & 66 \\
5 & 13.12 .26 & $2+$ & 71 \\
6 & 15.7 .9 & $2+$ & 73 \\
7 & 15.7 .9 & $2+$ & 67 \\
8 & 13.12 .26 & $2+$ & 70 \\
9 & 13.12 .26 & $2+$ & 69 \\
10 & 15.7 .9 & $2+$ & 71 \\
11 & 12.4 .6 & $2+$ & 69 \\
\hline Rata-rata & - & $2+$ & 71,27 \\
\hline
\end{tabular}

\section{Persentase Motilitas Individu Semen Sexing Beku pada Berbagai Perlakuan}

Pengamatan persentase motilitas spermatozoa dilakukan pada semen beku yang telah diberi perlakuan awal yang berbeda tidak menurunkan persentase motilitas individu pada semen sexing beku $(\mathrm{P}>0,05)$ (Tabel 2).

Tabel 2. Persentase motilitas individu semen sexing beku pada berbagai perlakuan

\begin{tabular}{cc}
\hline Perlakuan & Rata-rata $(\%)$ \\
\hline P1 semen beku X & $40,91 \pm 6,82$ \\
P2 semen beku X & $39 \pm 3,74$ \\
P3 semen beku X & $38,45 \pm 4,95$ \\
P1 semen beku Y & $40,09 \pm 5,8$ \\
P2 semen beku Y & $38,36 \pm 3,26$ \\
P3 semen beku Y & $37,91 \pm 4,7$ \\
\hline
\end{tabular}

Keterangan: P1: volume awal $1 \mathrm{ml}$; P2: volume awal $1,5 \mathrm{ml} ; \mathrm{P3}$ : volume awal $2 \mathrm{ml}$

Persentase motilitas tertinggi pada spermatozoa $\mathrm{X}$ diperoleh dari perlakuan P1 $(40,91 \pm 6,82 \%)$. Hal ini diduga disebabkan oleh volume semen awal yang digunakan lebih sedikit dibandingkan perlakuan lainnya, sehingga daya saing spermatozoa untuk memperoleh nutrisi lebih rendah dibandingkan pada perlakuan lainnya menggunakan volume semen awal yang lebih tinggi. Rataan spermatozoa Y tertinggi diperoleh dari perlakuan P1 $(40,09 \pm 5,8 \%)$. Hasil analisis menggunakan uji chi-square menunjukkan bahwa masingmasing perlakuan tidak mempengaruhi penurunan persetase motilitas semen beku hasil sexing $(\mathrm{P}>0,05)$, sehingga dapat dikatakan sesuai dengan persyaratan mutu SNI, untuk semen beku minimal memiliki persentase motilitas minimum 40\% (SNI-4869-1. 2017).

Pengaruh yang terdapat antar ulangan diduga disebabkan oleh penggunaan sapi pejantan yang tidak sama pada setiap ulangan, waktu dan lama koleksi semen, suhu lingkungan penampungan semen dan kondisi fisiologis ternak (libido pejantan), sehingga memberikan hasil yang tidak sama. Proses sexing hingga before freezing memerlukan waktu yang cukup lama, sehingga mempengaruhi persentase motilitas spermatozoa saat dilakukan uji kualitas pada penelitian ini. Susilawati (2013) menjelaskan bahwa kualitas semen dipengaruhi oleh individu sapi, pakan yang diberikan, libido dan proses penampungannya. 


\section{Konsentrasi Semen Sexing Beku pada Berbagai Perlakuan}

Pemeriksaan konsentrasi spermatozoa dalam satu straw semen beku setelah thawing untuk memastikan jumlah spermatozoa sesuai dengan SNI SNI 01-4869.1-2017.

Tabel 3. Konsentrasi spermatozoa semen sexing beku pada berbagai perlakuan

\begin{tabular}{cc}
\hline Perlakuan & Rata-rata (juta/straw) \\
\hline P1 semen beku Y & $25,23 \pm 0,93$ \\
P2 semen beku Y & $25,73 \pm 0,79$ \\
P3 semen beku Y & $26,18 \pm 1,63$ \\
P1 semen beku X & $23,09 \pm 1,36$ \\
P2 semen beku X & $23,41 \pm 0,89$ \\
P3 semen beku X & $23,86 \pm 2,32$ \\
\hline
\end{tabular}

Keterangan: P1: volume awal $1 \mathrm{ml} ; \mathrm{P} 2$ : volume awal 1,5 ml; P3: volume awal $2 \mathrm{ml}$

Berdasarkan hasil perhitungan, maka perlakuan P1, P2, dan P3 semen beku telah memenuhi persyaratan mutu SNI dan jumlah spermatozoa minimal pada semen beku adalah 25 juta spermatozoa/straw. Konsentrasi spermatozoa pada perlakuan lainnya belum memenuhi syarat mutu SNI yang telah ditetapkan. Mahfud et al. (2019) melaporkan bahwa jumlah spermatozoa semen sexing beku yang diperoleh dari semen beku adalah $12,125 \pm 4,19$ juta/straw. Hasil analisis menggunakan uji chi-square menunjukkan bahwa masing-masing perlakuan tidak mempengaruhi konsentrasi spermatozoa per straw $(\mathrm{P}>0,05)$, sehingga dapat dikatakan sesuai dengan persyaratan mutu SNI, yaitu 25 juta/straw (SNI4869-1.2017).

Hasil perhitungan konsentrasi semen beku sexing pada spermatozoa $\mathrm{X}$ yang tidak memenuhi persyaratan mutu SNI, hal ini diduga oleh proses pipetting (pengambilan lapisan bawah yang mengandung spermatozoa $\mathrm{X}$ ) pasca sexing yang kurang maksimal. Proses sexing spermatozoa menggunakan metode SGDP menghasilkan spermatozoa $\mathrm{X}$ pada lapisan bawah tidak memiliki warna yang kontras dengan medium sexing yang digunakan, sehingga pada saat pengambilan (pipetting) spermatozoa sering tercampur dengan gradien sexing. Hal ini mengakibatkan jumlah spermatozoa $X$ pada tahap semen cair (setelah sexing) lebih rendah dibandingkan dengan jumlah spermatozoa $\mathrm{Y}$ yang memiliki warna yang sangat kontras antara semen dengan medium sexing. Lebih jauh lagi, proses filling and sealing yang dilakukan secara manual mengakibatkan jumlah spermatozoa yang terkandung dalam satu straw tidak memiliki keteraturan (kesamaan) antar perlakuan.

\section{Persentase Viabilitas Semen Sexing Beku pada Berbagai Perlakuan}

Persentase viabilitas merupakan salah satu indikator fertilitas dan kualitas spermatozoa. Persentase viabilitas spermatozoa umumnya dinilai dari spermatozoa yang masih hidup yang dibandingkan dengan spermatozoa yang mengalami kerusakan selama pembekuan (Felipe-Pérez et al., 2008). Hasil pengamatan persentase viabilitas diperoleh hasil spermatozoa $\mathrm{X}$ dan $\mathrm{Y}$ dari masing-masing perlakuan (Tabel 4).

Tabel 4. Persentase viabilitas spermatozoa semen sexing beku pada berbagai perlakuan

\begin{tabular}{cc}
\hline Perlakuan & Rata-rata (\%) \\
\hline P1 semen beku Y & $23,86 \pm 8,85$ \\
P2 semen beku Y & $26,23 \pm 6,81$ \\
P3 semen beku Y & $30,33 \pm 14,53$ \\
P1 semen beku X & $24,20 \pm 7,57$ \\
P2 semen beku X & $23,35 \pm 10,11$ \\
P3 semen beku X & $32,33 \pm 11,47$ \\
\hline
\end{tabular}

Keterangan: Diantara perlakuan dan ulangan semen beku Y memberikan perbedaan pengaruh yang tidak nyata $(\mathrm{P}>0,05)$, sedangkan P1: volume awal $1 \mathrm{ml} ; \mathrm{P}$ : volume awal 1,5 ml; P3: volume awal 2 $\mathrm{ml}$

Berdasarkan data (Tabel 4) bahwa persentase viabilitas spermatozoa $\mathrm{X}$ dan $\mathrm{Y}$ pada perlakuan P3 memiliki persentase viabilitas tertinggi dibandingkan perlakuan lainnya. Rendahnya nilai persentase viabilitas spermatozoa diduga disebabkan oleh proses filling and sealing hingga proses before freezing, sehingga mengakibatkan rendahnya persentase viabilitas spermatozoa. Persentase viabilitas memiliki korelasi terhadap persentase motilitas. Hal ini sesuai dengan Susilawati (2014) bahwa persentase motilitas dan viabilitas spermatozoa berkaitan dengan kualitas membran sperma-tozoa. Kualitas membran yang buruk akan mempengaruhi persentase motilitas dan viabilitas spermatozoa. Proses sentrifugasi dan proses 
pembekuan spermatozoa dapat merusak membran spermatozoa, sehingga menyebabkan penurunan persentase motilitas dan viabilitas spermatozoa. Perlakuan volume semen awal yang berbeda tidak memiliki pengaruh terhadap viabilitas spermatozoa. Pengaruh yang terdapat antar ulangan diduga disebabkan oleh penggunaan sapi pejantan yang tidak sama pada setiap ulangan, waktu dan lama penampungan semen, suhu lingkungan saat penampungan semen dan kondisi fisiologis ternak (libido pejantan).

Proses pembekuan menyebabkan kerusakan pada membran plasma spermatozoa, sehingga kerusakan membran plasma tersebut memberikan celah untuk masuknya zat pewarna (eosin-negrosin) pada kepala spermatozoa yang menyebabkan timbulnya warna pada spermatozoa yang rusak (mati). Spermatozoa yang tidak mengalami kerusakan membran plasma tidak dapat menyerap zat warna, sehingga spermatozoa yang hidup tidak berwarna. Hal ini sesuai dengan Azzahra et al. (2016) bahwa persentase hidup spermatozoa ditentukan oleh adanya kerusakan pada membran plasma spermatozoa.

\section{Persentase Abnormalitas Semen Sexing Beku pada Berbagai Perlakuan}

Abnormalitas spermatozoa adalah kejanggalan bentuk fisik dari spermatozoa. Kejanggalan dapat berupa bentuk kepala yang meruncing dan kerusakan bagian kepala spermatozoa. Susilawati (2014) menyatakan bahwa abnormalitas spermatozoa dapat dibedakan menjadi dua, yaitu abnormalitas primer dan abnormalitas sekunder. Abnormalitas primer terjadi saat spermato-genesis di tubulus seminiferus testis dan faktor genetik, sedangkan abnormalitas sekunder dapat terjadi setelah spermatogenesis didalam tubulus seminiferus hingga semen diejakulasikan dan saat prosesing semen. Salim et al. (2012) menambahkan bahwa abnormalitas tersier memiliki ciri-ciri ekor yang terputus dari kepala spermatozoa. Data pengamatan abnormalitas spermatozoa dapat dilihat pada Tabel 5 .

Berdasarkan data pengamatan persentase abnormalitas semen sexing beku (Tabel 5) menunjukkan bahwa spermatozoa $\mathrm{Y}$ pada perlakuan P3 memiliki abnormalitas yang lebih tinggi dibandingkan perlakuan lainnya, sedangkan pada spermatozoa $\mathrm{X}$ terdapat persentase abnormalitas tertinggi pada perlakuan P2. Hal ini diduga oleh proses pembekuan yang dilakukan dan pembuatan preparat ulas sampel yang kurang baik. Persentase abnormalitas semen beku yang layak digunakan dalam pelaksanaan IB sebesar $<20 \%$ (Carvalho et al., 2010). Hasil tersebut sesuai dengan standar yang ditetapkan oleh Badan Standarisasi Nasional Indonesia (BSNI) tahun 2005 bahwa semen sapi memiliki morfologi abnormalitas, baik primer maupun sekunder, dibawah $20 \%$.

Tabel 5. Persentase abnormalitas semen sexing beku pada berbagai perlakuan

\begin{tabular}{cc}
\hline Perlakuan & Rata-rata (\%) \\
\hline P1 semen beku Y & $5,21 \pm 1,18$ \\
P2 semen beku Y & $4,40 \pm 1,27$ \\
P3 semen beku Y & $5,28 \pm 1,48$ \\
P1 semen beku X & $4,92 \pm 1,09$ \\
P2 semen beku X & $5,39 \pm 1,73$ \\
P3 semen beku X & $5,25 \pm 1,82$ \\
\hline
\end{tabular}

Keterangan: Diantara perlakuan memberikan perbedaan pengaruh yang tidak nyata $(\mathrm{P}>0,05$. P1: volume awal $1 \mathrm{ml}$; 2 : volume awal $1,5 \mathrm{ml} ; \mathrm{P} 3$ : volume awal $2 \mathrm{ml}$

Persentase dari hasil pengamatan abnormalitas spermatozoa menunjukkan persentase yang berbeda-beda pada masing-masing perlakuan, namun dengan perbedaan nilai persentase yang tidak terlalu jauh. Perlakuan volume semen awal yang berbeda tidak memiliki pengaruh terhadap abnormalitas spermatozoa. Pengaruh antar ulangan diduga disebabkan oleh penggunaan sapi pejantan yang tidak sama pada setiap ulangan, waktu dan lama koleksi semen, suhu lingkungan pengoleksian semen dan kondisi fisiologis ternak (libido pejantan).

\section{Total Spermatozoa Motil Semen Sexing Beku pada Berbagai Perlakuan}

Pengamatan total spermatozoa motil bertujuan untuk menentukan interpretasi nilai fertilitas spermatozoa berdasarkan jumlah konsentrasi da motilitas spermatozoa (Mahfud et al., 2019). Perhitungan total spermatozoa motil dapat dilihat pada Tabel 6 . 
Tabel 6. Total spermatozoa motil semen sexing beku pada berbagai perlakuan

\begin{tabular}{cc}
\hline Perlakuan & Rata-rata (juta/straw) \\
\hline P1 semen beku Y & $10,14 \pm 1,66$ \\
P2 semen beku Y & $9,87 \pm 0,88$ \\
P3 semen beku Y & $9,93 \pm 1,43$ \\
P1 semen beku X & $9,48 \pm 1,85$ \\
P2 semen beku X & $9,11 \pm 0,70$ \\
P3 semen beku X & $9,19 \pm 1,61$ \\
\hline
\end{tabular}

Keterangan: Diantara perlakuan memberikan perbedaan pengaruh yang tidak nyata $(\mathrm{P}>0,05$. P1: volume awal $1 \mathrm{ml} ; \mathrm{P} 2$ : volume awal $1,5 \mathrm{ml}$; P3: volume awal $2 \mathrm{ml}$

Berdasarkan data hasil penelitian (Tabel 6) menunjukkan bahwa rataan total spermatozoa motil tertinggi pada perlakuan P1 sebesar $(10,14 \pm 1,66$ juta/straw $)$ untuk spermatozoa Y dan $9,48 \pm 1,85$ juta/straw untuk spermatozoa $\mathrm{X}$, sedangkan nilai ekspektasi total spermatozoa motil sebesar 10 juta/straw. Hasil tersebut dipengaruhi oleh persentase motilitas spermatozoa X dan Y pada perlakuan P1 lebih tinggi dibandingkan dngan perlakuan yang lain.

Hasil perhitungan total spermatozoa motil menggunakan uji chi-square pada perlakuan P1 semen beku X dan Y sudah memenuhi persyaratan mutu yang ditetapkan BSNI ( $P>0,05)$ (BSNI, 2005), sehingga dapat dikatakan sesuai semen beku minimal memiliki total spermatozoa motil 10 juta/straw (SNI4869-1. 2017). Perlakuan volume semen awal yang berbeda tidak memiliki pengaruh terhadap total spermatozoa motil. Pengaruh antar ulangan diduga disebabkan oleh penggunaan sapi pejantan yang tidak sama pada setiap ulangan, waktu dan lama penampungan semen, suhu lingkungan saat penampungan semen dan kondisi fisiologis ternak (libido pejantan).

\section{Persentase Recovery Rate (RR) Semen Sexing Beku pada Berbagai Perlakuan}

Recovery rate merupakan pemulihan spermatozoa setelah setelah pembekuan dengan cara membandingkan motilitas spermatozoa setelah thawing dengan motilitas spermatozoa segar (Garner dan Hafez, 2000). Arifiantini et al. (2005) melaporkan bahwa persentase nilai RR pada semen beku sapi Freisian Holstein menggunakan pengencer berbeda adalah $69,56 \pm 11,32 \%$ untuk pengencer mengandung kacang kedelai, $63,48 \pm 9,25 \%$ untuk pengencer
Tris raffinose dan $59,40 \pm 11,24 \%$ untuk pengencer Tris fructose. Nilai rata-rata RR dari masing-masing perlakuan spermatozoa $\mathrm{X}$ dan $\mathrm{Y}$ dapat dilihat pada Tabel 7.

Hasil yang diperoleh dari perhitungan persentase nilai RR menunjukkan bahwa perlakuan P1 semen beku X $(57,63 \pm 10,58 \%)$ dan Y $(56,54 \pm 9,69 \%)$ mempunyai nilai tertinggi dibandingkan dengan perlakuan lainnya (Tabel 7). Hasil ini diduga disebabkan oleh persentase motilitas individu masingmasing perlakuan pada spermatozoa $\mathrm{X}$ dan $\mathrm{Y}$ tidak jauh berbeda, sehingga menyebabkan nilai RR yang diperoleh tidak memiliki perbedaan antar perlakuan. Pengaruh antar ulangan diduga disebabkan oleh penggunaan sapi pejantan yang tidak sama pada setiap ulangan, waktu dan lama penampungan semen, suhu lingkungan saat penampungan semen dan kondisi fisiologis ternak (libido pejantan). Sunami et al. (2017) melaporkan bahwa nilai RR sapi Limousin pada musim yang berbeda dengan nilai $R R$ tertinggi $62 \pm 0,03 \%$ pada musim hujan dan $67 \pm 0,05 \%$ pada musim kemarau., Berdasarkan hasil penjelasan tersebut, maka nilai RR tertinggi hasil penelitian ini (perlakuan P1 semen beku Y dan X) berada dibawah hasil penelitian Sunami et al. (2017).

Tabel 7. Persentase nilai recovery rate pada berbagai perlakuan

\begin{tabular}{cc}
\hline Perlakuan & Recovery Rate (\%) \\
\hline P1 semen beku Y & $56,54 \pm 9,69$ \\
P2 semen Beku Y & $54,03 \pm 6,06$ \\
P3 semen beku Y & $53,41 \pm 7,83$ \\
P1 semen beku X & $57,63 \pm 10,58$ \\
P2 semen Beku X & $54,92 \pm 6,62$ \\
P3 semen beku X & $54,15 \pm 7,97$
\end{tabular}

Keterangan: Diantara perlakuan memberikan perbedaan pengaruh yang tidak nyata $(\mathrm{P}>0,05$. $\mathrm{P} 1$ : volume awal $1 \mathrm{ml} ; \mathrm{P} 2$ : volume awal $1,5 \mathrm{ml}$; P3: volume awal $2 \mathrm{ml}$

\section{Proporsi Spermatozoa Semen Sexing Beku pada Berbagai Perlakuan}

Sexing merupakan upaya untuk mengubah proporsi-proporsi alamiah spermatozoa $\mathrm{Y}$ dan X (50\%:50\%) menjadi proporsi yang diinginkan dengan menggunakan metode sexing tertentu (Afiati, 2016). Persentase rataan proporsi spermatozoa $\mathrm{X}$ dan Y dapat dilihat pada Tabel 8. 
Tabel 8. Proporsi spermatozoa pada berbagai perlakuan

\begin{tabular}{cc}
\hline Perelakuan & Rata-rata (\%) \\
\hline P1 semen beku Y & $80,64 \pm 2,94$ \\
P2 semen beku Y & $81,64 \pm 3,67$ \\
P3 semen beku Y & $83,18 \pm 1,99$ \\
P1 semen beku X & $73,45 \pm 3,72$ \\
P2 semen beku X & $74,00 \pm 3,82$ \\
P3 semen beku X & $74,64 \pm 4,57$ \\
\hline
\end{tabular}

Keterangan: Diantara perlakuan memberikan perbedaan pengaruh yang tidak nyata $(\mathrm{P}>0,05$. $\mathrm{P} 1$ : volume awal $1 \mathrm{ml} ; \mathrm{P} 2$ : volume awal 1,5 ml; P3: volume awal $2 \mathrm{ml}$

Hasil yang didapat pada spermatozoa $\mathrm{Y}$ masing-masing perlakuan sebesar $80,64 \%(\mathrm{P} 1)$; $81,64 \%$ (P2) dan $83,18 \%$ (P3) telah memenuhi nilai ekspektasi sexing spermatozoa, yaitu 80\%:20\%. Spermatozoa $\mathrm{X}$ dari perlakuan yang berbeda adalah $73,45 \%(\mathrm{P} 1) ; 74 \%(\mathrm{P} 2)$ dan $74,64 \%$ (P3) dan nilai proporsi tersebut belum memenuhi nilai ekspektasi sexing spermatozoa. Hal ini diduga terjadi kesalahan pada proses pipetting saat koleksi spermatozoa $\mathrm{X}$ dan kemungkinan terambil spermatozoa $\mathrm{Y}$ yang berada di fraksi atas pada saat sexing. Perlakuan volume semen awal yang berbeda tidak memiliki pengaruh terhadap proporsi spermatozoa. Fatahillah et al. (2016) melaporkan bahwa persentase spermatozoa $X$ semen sapi Limousine adalah $54,60 \pm 10,76 \%$ dan

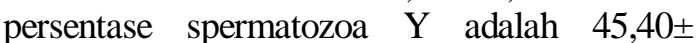
$10,76 \%$. Berdasarkan hasil penelitian tersebut, bahwa IB menggunakan semen beku yang mengandung spermatozoa $\mathrm{Y}$ kemungkinan pedet yang akan dilahirkan adalah pedet jantan, karena rataan persentase spermatozoa Y lebih tinggi dibandingkan spermatozoa $\mathrm{X}$.

\section{KESIMPULAN}

Hasil penelitian menunjukkan bahwa perlakuan volume tidak memberikan pengaruh terhadap rataan persentase motilitas, konsentrasi, persentase viabilitas, persentase abnormalitas, persentase recovery rate, total spermatozoa motil dan proporsi spermatozoa.

\section{DAFTAR PUSTAKA}

Afiati, L. 2004. Proporsi dan karakteristik spermatozoa $\mathrm{X}$ dan $\mathrm{Y}$ hasil separasi kolom albumin. Media Peternakan 27 (1):16-20.
Arifiantini, I., T.L. Yusuf, \& N. Graha. 2005. Longitivitas dan recovery rate pasca thawing semen beku sapi friesian holstein menggunakan bahan pengencer yang berbeda. Buletin Peternakan 29(2):53-61.

Azzahra, F.Y., E.T. Setiatin, \& D. Samsudewa. 2016. evaluasi motilitas dan persentase hidup semen segar sapi PO Kebumen pejantan muda. Jurnal Sains Peternakan Indonesia 11(2):99-107.

[BSNI] Badan Standarisasi Nasional Indonesia. 2005. Semen Beku Sapi. [SNI-014869.12005]. Badan Standarisasi Nasional Indonesia. Jakarta.

[BSNI] Badan Standarisasi Nasional Indonesia. 2017. Semen Beku-Bagian 1: Sapi. [SNI-4869-1]. Badan Standarisasi Nasional Indonesia. Jakarta.

Carvalho, J.O., R. Sartori, G.M. Machado, G.B. Mourão, \& M.A.N. Dode. 2010. Quality assessment of bovine cryopreserved sperm after sexing by flow cytometer and their use in vitro embryo production. Theriogenology 74:1521-1530.

Fatahillah, T. Susilawati, \& N. Isnaini. 2016. Pengaruh lama sentrifugasi terhadap kualitas dan proporsi spermatozoa X-Y sapi Limousine hasil sexing dengan gradien densitas percoll menggunakan pengencer CEP-2+10\% KT. Jurnal Ternak Tropika 17(1):86-97.

Felipe-Pérez. Y.E., M.L Juárez-Mosqueda, E.O. Hernández-González, \& J.J Valencia. 2008. Viability of fresh and frozen bull sperm compared by two staining techniques. Acta Veterinaria Brasilica 2(4):123-130.

Fernanda, M.T., T. Susilawati, \& N. Isnaini. 2014. Keberhasilan IB menggunakan semen beku hasil sexing dengan metode sentrifugasi gradien densitas percoll (SGDP) pada Sapi Peranakan Ongole (PO). Jurnal Ilmu-Ilmu Peternakan 24(3):1-8.

Garner, D.L. \& E.S.E. Hafez. 2000. Preservation and cryopreservation of gametes and embryos. In Reproduction in Farm Animals. $7^{\text {th }}$ Edited by Hafez 
E.S.E. and B. Hafez. Lippincot Williams \& Wilkins Philadelphia (Pennsylvania).

Mahfud, A., N. Isnaini, A.P.A. Yekti, Kuswati, \& T. Susilawati. 2019. Kualitas spermatozoa post thawing semen beku sperma $y$ hasil sexing pada sapi Limousin. Jurnal Ternak Tropika 20(1): 1-7.

Noakes, D.E., T.J. Parkinson, \& G.C.W. England. 2009. Veterinary reproduction and obstetrics. Edition $9^{\text {th }}$. Elsevier Inc. London.

Salim, M.A, T. Susilawati, \& S. Wahyuningsih. 2012. Pengaruh metode thawing terhadap kualitas semen beku sapi bali, sapi madura dan sapi PO. Agripet 12(2):14-20.

Sunami, S., N. Isnaini, \& S. Wahjuningsih. 2017. Kualitas semen segar dan recovery rate (RR) sapi Limousin pada musim yang berbeda. Jurnal Ternak Tropika 18(1):36-50.
Susilawati, T. 2011. Spermatology. UB Press. Malang.

Susilawati, T. 2013. Pedoman Inseminasi Buatan Pada Ternak. UB Press. Malang.

Susilawati, T. 2014. Sexing Spermatozoa. Hasil Penelitian Laboratorium dan Aplikasi pada Sapi dan Kambing. UB Press. Malang.

Susilawati, T., E. D. Kusumawati, N. Isnaini, A. P. A. Yekti, H. Sudarwati, \& A. Ridhowi. 2017. Effect of sexing process using percoll density gradien centrifugation and frozen on motility and damage to spermatozoa membrane of filial Ongole. Animal in Healt Science Research. 5: 227-231.

Susilawati, T. \& A.P.A. Yekti. 2018. Teknologi Inseminasi Buatan Menggunakan Semen Cair (Liquid Semen). UB Press. Malang. 